\title{
Plantas alimentícias não convencionais em Belém, Pará: conhecimento, usos e segurança alimentar
}

\section{Non-conventional food plants in Belém, Pará: knowledge, uses and food security}

Délio Reis Matos de Aquino - Mestre em Gestão dos Recursos Naturais e Desenvolvimento Local na Amazônia, pela Universidade Federal do Pará (UFPA). Professor de História e Estudos Amazônicos na EEEFM Mário Barbosa. E-mail: delio_reis@yahoo.com.br

Maria do Socorro Almeida Flores - Doutora em Direitos Humanos e Meio Ambiente, pela Universidade Federal do Pará (UFPA). Pesquisadora e Docente Permanente do Programa de Pós-Graduação em Gestão dos Recursos Naturais e Desenvolvimento Local na Amazônia (PPGEDAM) do Núcleo de Meio Ambiente (NUMA) da UFPA. E-mail: saflores@ufpa.br

\section{Resumo}

A pesquisa situa-se no contexto das plantas alimentícias não convencionais (PANC) e tem como objetivo principal observar os conhecimentos e o uso destas plantas como alimento na cidade de Belém-PA, especificamente no bairro da Terra Firme, onde se fez um levantamento no ambiente da Escola Estadual "Mário Barbosa". A pesquisa básica, qualitativa e descritiva foi realizada no período entre os meses de novembro de 2017 até novembro de 2019. Faz referência à segurança alimentar, apontando para uma possível aplicabilidade futura como instrumento para o desenvolvimento local e que também contribua para a sustentabilidade da diversidade vegetal. Inclui importante literatura científica referente aos conhecimentos históricos e culturais dessas plantas, assim como em outras áreas de conhecimento a exemplo da botânica, biologia, agricultura e demais competências acadêmicas que possibilitam saberes, os quais legitimam o uso destas plantas como alimento.

\section{Palavras-chave}

Plantas alimentícias não convencionais. Desenvolvimento Local. Diversidade vegetal. Segurança alimentar.

\begin{abstract}
The research is located in the context of unconventional food plants (PANC) and its main objective is to observe the knowledge and use of these plants as food in the city of Belém-PA, specifically in the Terra Firme neighborhood, where a survey was carried out in the environment of the State School "Mário Barbosa". Basic, qualitative and descriptive research was carried out between November 2017 and November 2019. It refers to food security, pointing to a possible future applicability as an instrument for local development and that also contributes to the sustainability of diversity vegetable. It includes important scientific literature regarding the historical and cultural knowledge of these plants, as well as in other areas of knowledge such as botany, biology, agriculture and other academic skills that enable knowledge, which legitimize the use of these plants as food.
\end{abstract}

\section{Keywords}

Unconventional food plants. Local development. Vegetable diversity. Food security. 


\section{INTRODUÇÃO}

As duas primeiras décadas deste século evidenciam um contexto de enorme inquietação quanto às questões referentes às dimensões físico-químicas que compõem o macro sistema do ambiente biosférico do planeta Terra. Um reflexo bastante realista desse axioma sobre a qualidade socioambiental contemporânea e a busca por soluções estão muito bem exemplificados nos 17 objetivos da Agenda 2030, que é fruto do trabalho conjunto de governos e cidadãos de todo o mundo para criar um novo paradigma mundial e acabar com a pobreza, promover a prosperidade e o bem-viver de todos (AGENDA 2030, 2015).

Nessecontexto, os estudos sobre as Plantas Alimentícias Não Convencionais (PANC) propõem mais uma alternativa extrativa e agriculturável à margem do sistema econômico ortodoxo do agronegócio. Enquanto as PANC fazem parte de uma oferta potencial de alimentos de pelo menos 30 mil plantas diferentes no mundo, "o agronegócio capitalista limita 50\% das calorias consumidas no mundo a no máximo quatro espécies de plantas e $90 \%$ dos alimentos consumidos vêm de somente 20 tipos de plantas" (KELEN, 2015, p. 8).

As plantas alimentícias utilizadas em comunidades, regiões ou países, mas que não são conhecidas pelas grandes populações locais e mundiais, receberam em cada cultura e em diversos contextos históricos, várias denominações, especialmente nos momentos de grande dificuldade para encontrar alimentos como, por exemplo: períodos de grandes guerras ou mudanças climáticas que atingiram violentamente a organização produtiva de vegetais que já estavam domesticados, reconhecidos e arraigados na agricultura das populações em vários lugares do planeta.

A Fitoalimurgia, vocábulo cunhado no Século XVIII em um período de escassez de alimento, deriva de três palavras gregas phyto $=$ planta; alimos $=$ que sacia e ergon = trabalho ou atividade, para significar o estudo das plantas com fins de alimentar as pessoas colhendo o que a natureza oferece. Termo retomado no Século XX no primeiro pós-guerra, quando a busca por alimentos foi primordial e a natureza supriu essa necessidade. Atualmente, significa também redescobrir e respeitar tudo aquilo que nos circunda (KINUPP, 2014, p. 15).

Portanto, justifica-se o conhecimento sobre as PANC como uma contribuição para demonstrar como muitas plantas conceituadas como daninhas, viabilizam aumentar a variedade de produtos no mercado e contribuir para a qualidade nutricional, ampliação da diversidade de alimentos produzidos em âmbito local e contribuir com alimentação saudável e adequada da Merenda Escolar nos ambientes de escolas públicas do Estado do Pará, atendendo aos 
objetivos propostos na Lei Federal n 11.947/2009 (BRASIL, 2009), que instituiu o Programa Nacional de Alimentação Escolar (PNAE) (BRASIL, 1988).

O conhecimento e o uso das PANC serão, portanto, objeto de análise do presente estudo, em Belém-PA, especificamente no ambiente da Escola Estadual de Ensino Fundamental e Médio (E.E.E.F.M.) "Mário Barbosa", localizada, no bairro da Terra Firme, no Distrito Administrativo do Guamá - DAGUA, um dos mais pobres e violentos da cidade de Belém (LARRAT, 2013). Inaugurada em 1994, a escola agrega no seu quadro discente crianças e jovens residentes do próprio bairro e da comunidade Nossa Senhora dos Navegantes, localizada na bacia do Rio Aurá. A maioria das famílias tem renda mensal baseada em um salário-mínimo e muitas possuem renda abaixo desses proventos, portanto o Programa Nacional de Merenda Escolar é de extrema importância para a maioria dos discentes.

As instalações da escola estão estabelecidas em um terreno com mais de $12.850^{2}$ (PIMENTEL, 2015), com muitas áreas livres, onde se desenvolvem plantas cultivadas e plantas espontâneas. As espontâneas em sua resiliência vencem ano a ano as diversas roçagens executadas periodicamente pela gestão, no entanto desde março de 2018 se executa o manejo das Plantas Alimentícias Não Convencionais, uma vez que vem sendo reconhecida sua importância como recurso natural fundamental e como estratégia para alcançar melhor qualidade nutricional dos discentes.

A partir dessas evidências se estabeleceu como objetivo geral deste estudo realizar o levantamento das Plantas Alimentícias Não Convencionais presentes no ambiente da E.E.E.F.M. "Mário Barbosa" sob a ótica dos saberes locais, dos conhecimentos científicos, usos, qualidades alimentícias e nutricionais desses vegetais.

Os objetivos específicos delineados na pesquisa se pautaram em identificar as PANC e suas qualidades nutricionais no ambiente da referida escola e em seu entorno; observar a interação (conhecimentos, usos) da comunidade escolar com as PANC, no contexto do ambiente educacional formal e informal desenvolvidos na E.E.E.F.M. "Mário Barbosa"; propor uma experiência de manejo e cultivo das PANC nos diversos ambientes livres da instituição de ensino para o uso e consumo via merenda escolar.

Para alcançar as metas do primeiro objetivo específico realizou-se uma revisão da bibliografia referente às PANC, quando se executou o exame e análise de trabalhos de monografias, dissertações, teses, artigos, guias e livros sobre a diversidade de plantas alimentícias e suas qualidades nutricionais no Brasil e na Amazônia, dentre os estudiosos no assunto figuram nessa lista: Aquino (2017), 
Brasil (2010a, 2015), Cavalcante (2010), Duarte (2017), Dia de campo... (2018), Kinupp (2007, 2009, 2014), Lisboa (2009) e Pesce (2009), além de consultas da produção acadêmica de especialistas biólogos, botânicos e taxonomistas.

As fontes documentais sobre o assunto foram pesquisadas em instituições como Embrapa, INPA e Museu Paraense Emílio Goeldi, apenas neste último, foi realizada pesquisa presencial na Estação Científica Ferreira Pena. Nas demais instituições a coleta de dados foi realizada a partir dos bancos de dados disponíveis na internet.

Para o trabalho de campo foi utilizado como ferramenta metodológica o método de observação a partir do caminhamento como propõe Duarte (2017), que consiste em percorrer uma determinada área urbana ou não urbana com o objetivo de identificar espécies, até que não sejam encontradas novas espécies naquela área de estudo, empregando um levantamento do trajeto percorrido. O método escolhido visou o reconhecimento das espécies classificadas como PANC, elaboração de uma lista de espécies encontradas na área de estudo, bem como posterior análise dos dados.

O caminhamento se realizou entre os meses de novembro de 2017 a novembro de 2019, nos mais de $12.850^{2}$ que formam o ambiente da escola e nas ruas do seu entorno. De acordo com o método adotado anotou-se o nome popular das espécies, produziu-se fotografias e vídeos com um aparelho celular Samsung S7. Para alcançar as metas do segundo e terceiro objetivos específicos foi utilizado o método da Observação Participante fundamentado em Malinowski (1978), Severino (2016), além de Ezpeleta e Rockwell (1989).

$\mathrm{Na}$ Observação Participante, inaugurada pelo antropólogo Bronislaw Kasper Malinowski a partir de sua convivência com os nativos de Mailu e demais tribos da Nova Guiné, os quais participavam do Kula, um sistema de troca comercial intertribal consiste, antes de tudo, em uma convivência prolongada com os sujeitos estudados no processo de pesquisa. No caso de Malinowski (1978) o objetivo era observar, entender, analisar e produzir conhecimento científico abrangendo com profundidade todos os aspectos antropológicos próprios daquelas tribos: a língua, organização social, economia, religiosidade, constituição familiar, o sistema alimentar e todas as dimensões concernentes à cultura como propõe Brandão (2009).

\section{REVISITANDO AS PANC}

O estudo sobre as PANC tem relevância histórica tanto para o estudo do passado e principalmente para a história contemporânea do Brasil. D’Abbeville 
(1874), D’Évreux (2007), Fernandes (2016), Gândavo (2004), Lopes (2017), Souza (2000) e Veríssimo (2013) são importantes referências sobre os estudos do início da invasão europeia sobre os territórios indígenas a partir do século XVI, quando confirmam a opulenta biodiversidade de plantas alimentícias conhecidas, manejadas e cultivadas pelos povos indígenas.

Nesse sentido, o estudo das PANC além de contribuir para decolonizar o pensamento, promover e dinamizar a convivência simultânea de saberes como propõe Walsh (2009), superar a monocultura do saber como postula Santos (2006) e combater o analfabetismo botânico conforme Kinupp (2009) se apresenta como uma alternativa à margem do sistema econômico hegemônico, para auxiliar no combate à fome, à desnutrição e também à dependência que atualmente muitos agricultores brasileiros vivenciam em relação às grandes corporações que já privatizaram, controlam a produção e o comércio de semente de muitas plantas, hoje, classificadas como convencionais, o que força a dependência dos produtores em relação a essas corporações (ARDISSONE et al., 2009).

Enquanto essa agricultura hegemônica é imposta na história agronômica da maioria dos países na atualidade, as PANC que em sua grande maioria são espontâneas, de pujante resiliência, se oferecem como recursos naturais pelas calçadas, sarjetas, terrenos baldios, quintais, passíveis de domesticação (ARRUDA, 1999), onde, no mínimo, os habitantes de uma comunidade ou os discentes do ensino básico de um educandário podem obter gratuitamente, as sementes e/ou as mudas necessárias para iniciar e dinamizar o cultivo ou manejo em espaços livres (AQUINO, 2020), fora dos ambientes profundamente antropizados nos quais essas plantas se reproduzem na realidade urbanística de Belém, o que liberaria também, as condições iniciais para a busca por segurança e soberania alimentar dos sujeitos históricos envolvidos no processo da pesquisa e da possível aplicabilidade dos resultados (AQUINO, 2017).

O lugar de nascimento de qualquer sujeito histórico, seus atributos e elementos constituintes da sua natureza, sobretudo quando os direitos humanos e direitos fundamentais são respeitados, se engendra na singularidade irredutível do indivíduo (BOFF, 2012, p. 157), compondo um sentido benéfico nas dimensões do corpo, da memória e da cultura, como apregoa Brandão (2009), por toda a história socioambiental deste. A partir da educação formal e informal esses conhecimentos sobre o cultivo e manejo das PANC poderão ser replicados junto aos familiares dos discentes contribuindo também para a sustentabilidade, o amparo e a conservação da biodiversidade vegetal da Amazônia.

Portanto, o escopo deste trabalho abaliza a finalidade de combater o desconhecimento botânico e se propõe servir como estratégia eficaz para 
contribuir com a busca da segurança e soberania alimentar no contexto da sociedade belenense, visto que as PANC já estão presentes na organização de novos assentamentos como se observou em acampamentos de camponeses do MST no Estado do Rio Grande do Sul, que passaram a coletar várias dessas plantas às margens das estradas, jardins e nos quintais (MOLDELSK, 2015), e também como insumos da alta gastronomia em cidades brasileiras, a exemplo de Manaus (JORNAL DIÁRIO DO AMAZONAS, 2016), Porto Alegre (RESTAURANTE..., 2017), Rio de Janeiro e São Paulo (FRANÇA, 2017), e aí se indica os diferentes potenciais desse recurso natural.

Também pode ser pensada como uma ferramenta para a sustentabilidade da diversidade vegetal que promova a compreensão mais eficaz do uso das PANC, o que poderá fortalecer a produção econômica da cidade de Belém, no sentido que essas plantas podem aumentar a oferta mais plural de alimentos, por conseguinte promover, diversificar melhorar a qualidade nutricional e a saúde da população (AQUINO, 2017).

As PANC possibilitam o acesso às mudas e sementes, motivam o aprendizado de cultivo e manejo desses vegetais, podem gerar excedentes para a comercialização, ampliam a visão de segurança e soberania alimentar e articulam a convivência positiva com um simultâneo de culturas no cotidiano das comunidades apontando para a promoção do desenvolvimento local (EPAGRI, 2020) e do bem-viver destas (ALCANTARA; SAMPAIO, 2017).

Segundo o Professor Dr. Valdely Kinupp as PANC, ainda que denominadas "daninhas" ou "inços" silvestres possuem importante relevância ecológica possuindo partes comestíveis e utilizadas na alimentação humana (KINUPP, 2007, p. 29), portanto podem ser categorizadas como recursos naturais no sentido proposto por Fenzl (1998) podendo contribuir com grande potencial para o desenvolvimento local, no sentido de garantir a produção de alimentos para a família, aumentar a renda com os excedentes, promover maior diversidade de produtos alimentícios, assim como melhorar a qualidade nutricional e por consequência a saúde dos consumidores (KINUPP, 2014).

Fica definido como desenvolvimento local, o que apresenta a Agenda 2030 no seu objetivo 3 (três) que propõe a eliminação da pobreza e da fome no Planeta, o combate às desigualdades entre os países, a edificação de sociedades pacíficas, justas e inclusivas, a proteção dos direitos humanos, a igualdade de gênero com força para as mulheres e meninas, assegurar a permanente proteção dos recursos naturais da Terra. Bem como promover as condições para um aumento da sustentabilidade econômica, ambiental e socialmente inclusiva com a prosperidade compartilhada e trabalho digno para todos, considerando 
os diferentes níveis de desenvolvimento e capacidades dos países (AGENDA 2030, 2015, p. 3).

A produção de alimentos neste momento da história da humanidade é suficiente para alimentar a todos (COGGIOLA, 2010; DUARTE, 2017; REVISTA KATÁLYSIS, 2014), no entanto é impactante o número de pessoas que não possuem segurança alimentar e por consequência 42,5 milhões de pessoas conviveram com o problema da fome na América Latina e no Caribe em 2018 (A FOME..., 2019).

As projeções da FAO indicam uma população em crescimento até 2050, em um cenário no qual as mudanças climáticas possuem impacto negativo sobre a produção alimentícia (DUARTE, 2017, p. 29), evidenciando as contradições da produção de alimentos no macrossistema hegemônico da contemporaneidade.

No Brasil a instituição da Lei Orgânica de Segurança Alimentare Nutricional (LOSAN), a Lei Federal n. ${ }^{\circ} 11.346 / 2006$ (BRASIL, 2006), regulamentada pelo Decreto Federal n. ${ }^{\circ}$ 7.272/2010 (BRASIL, 2010b), representa um marco fundamental na luta nacional contra a fome, pois através dela criou-se o Sistema de Segurança Alimentar e Nutricional (SISAN), que busca promover condições para a formulação da Política e do Plano Nacional na área de segurança e soberania alimentar, que tem como fundamento desenvolver diretrizes e metas, além de captar recursos e fomentar instrumentos de avaliação e monitoramento em um conjunto de ações e programas integrados, inter-relacionando diferentes setores do Estado, governos e a sociedade, com o objetivo de garantir alimentação regular e de qualidade para toda a sociedade brasileira (AQUINO, 2017).

O Programa Nacional de Alimentação Escolar (PNAE), instituído pela Lei Federal n 11.947/2009 (BRASIL, 2009), também se concilia com a riqueza nutricional, o desenvolvimento espontâneo, produção orgânica e a possibilidade de desenvolvimento sustentável que as PANC promovem além de contribuir com a sustentabilidade da diversidade vegetal local, especialmente se associada com produtores familiares rurais e com a cultura das comunidades locais quando dispõe sobre suas diretrizes sobre o emprego da alimentação saudável e adequada (BRASIL, 1988).

No âmbito local, desde a década de 1990, já estava prevista uma Política de Abastecimento Alimentar inserida no $1^{\circ}$ Plano Diretor do Município de Belém - Lei Municipal n. ${ }^{\text {7 7.603, de }} 13$ de janeiro de 1993 (BELÉM, 1993). Para assegurar e atender as necessidades nutricionais dos seus habitantes, em especial os de baixa renda. Na contramão dos princípios, objetivos e políticas da legislação sobre segurança alimentar no nosso país o Instituto Brasileiro de 
Geografia e Estatística (IBGE) (RENAUX, 2018) anuncia que mais de 1/4 da população brasileira está abaixo da linha da pobreza, em 2017.

Somado a estas realidades temos o desperdício alimentar ocasionado por fatores distintos em países desenvolvidos e em desenvolvimento. "Nos países em desenvolvimento, o desperdício dá-se pela falta de infraestrutura, ausência de tecnologia no armazenamento e transportes, técnicas de cultivo" (DUARTE, 2017, p. 29). É no bojo desde contexto que o professor Dr. Valdely Kinupp inicia os estudos sobre as Plantas Alimentícias Não Convencionais em 1997, na Universidade Federal do Rio Grande do Sul (UFRGS), com a pesquisa de sua tese de doutorado.

Instituições com excelência na produção científica sobre os vegetais alimentícios a exemplo da FAPEG (Fundação de Amparo à Pesquisa do Estado de Goiás) e da Embrapa (Empresa Brasileira de Pesquisa Agropecuária) que, em 2018 realizou o II Encontro Nacional de Hortaliças não Convencionais com o objetivo de desenvolver um foco maior em agricultura urbana, mas também com o propósito de aproximar agricultores e consumidores das Hortaliças Não Convencionais (HortPANC). Dessa vez, além da zona rural, espaços urbanos como praças, lajes e escolas também receberam oficinas com as hortaliças que fazem parte do grupo das PANC. Assim como propôs aproximar profissionais de diferentes setores relacionados às "hortaliças não convencionais - produtores, pesquisadores, nutricionistas, médicos, chefs de cozinha - para favorecer a realização de ações que promovam o cultivo e o consumo dessas espécies pela população" (DIA DE CAMPO..., 2018, p. 1).

A diversidade desses vegetais no Município de Belém Pará, o conhecimento e uso de várias espécies de plantas, assim como outras desta mesma classificação que ainda não faziam parte da alimentação dos belenenses, evidenciando a importância das PANC como elementos estratégicos do contingente de recursos naturais alimentícios e as perspectivas dessas plantas nas dimensões de estratégia e instrumentos para o desenvolvimento local e a sustentabilidade da diversidade vegetal. Foi registrada em 2017 no estudo sobre plantas alimentícias não convencionais no contexto da educação ambiental, realizado na comunidade Nossa Senhora dos Navegantes (Ilha da Várzea do Rio Aurá), no município de Belém (AQUINO, 2017).

Outros marcos teóricos importantes para os estudos de plantas alimentícias na Amazônia estão embasados nas obras clássicas de Cavalcante (2010), Lisboa (2009) e Pesce (2009), além de literaturas específicas relacionadas à história da alimentação e história das agriculturas embasadas nas obras de Flandrin (2015) e Mazoyer (2010). 


\section{RESULTADOS E DISCUSSÃO}

A E.E.E.F.M. "Mário Barbosa”, instituição educacional pública estadual, que segundo Pimentel (2015) foi construída em amplo terreno retangular de aproximadamente $12.850 \mathrm{~m}^{2}$, espaço onde se executou a Observação Participante, se delineou saber com acuidade à interação das pessoas que compõem a comunidade escolar e as plantas alimentícias, em geral 18 plantas, das quais 15 são classificadas como PANC por Kinupp (2014) e especificamente o conhecimento e o uso das PANC pelos comunitários. A interação com a referida comunidade escolar já se estende por 22 anos e a Observação Participante está em processo desde 2016.

A Observação Participante se realizou primeiro a partir das plantas convencionais, a exemplo da Manga Bacuri, (Mangifera indica L.), quando na safra de 2018 se mobilizou setores da comunidade escolar para ter o máximo controle sobre o período em que os frutos já poderiam ser consumidos até a sua plena maturação. Os setores participantes foram: a Direção e Vice-direção, Corpo Técnico Pedagógico, inspetores de pátio, pessoal de apoio (limpeza e arrumação), pessoal da portaria e segurança, cozinheiros e professores.

Todos agiam nos três turnos no sentido em manter a permanência dos frutos até o período apropriado da colheita. Quando os frutos foram colhidos se ofereceu para os servidores de todos os seguimentos participantes e para os estudantes dos ensinos fundamental e médio. A receptividade foi positiva entre as pessoas de todos os setores observados.

Além da Manga bacuri mais dois vegetais convencionais foram produzidos no ambiente da escola com o conceito de "experimento", para oportunizar outros momentos da Observação Participante. Os vegetais escolhidos foram a couve-manteiga (Brassica oleracea) e o quiabo (Abelmoschus esculentus).

Quinze estudantes do ensino fundamental aceitaram participar de todo o processo produtivo. Observou-se que mesmo antes da maturação das folhas de couve as cozinheiras iam até o ambiente do experimento e as colhiam, é fundamental informar que não foram pré-anunciadas regras no sentido de colher ou não colher os produtos. Observou-se também a colheita dos quiabos pelas cozinheiras. Quanto aos estudantes apenas três aceitaram levar couves e quiabos para suas residências, assim como um professor e uma vice-diretora.

Outros vegetais convencionais observados foram o Taperebá (Spondias mombin L.) e o Coco Amarelo (Cocos nucifera). No período em que os taperebás estão maduros e caindo, mesmo em ambiente sem roçagem, pessoas de todos os setores da comunidade escolar se encaminham até o local e coletam os frutos. 
Seis estudantes do ensino médio foram observados subindo na árvore para coletar os frutos.

O único pé de coqueiro existente no ambiente da escola está plantado no terreno próximo aos fundos da Sala de Professores. Os vidros das janelas estão protegidos por películas escuras e é possível observar com tranquilidade os estudantes que colhem os frutos. Depois que os cocos são retirados da palmeira, acomoda-os nas mochilas escolares e os carregaram para fora do ambiente escolar aparentemente sem nenhuma autorização ou controle institucional.

Quanto as 15 Plantas Alimentícias Não Convencionais presentes no terreno do educandário somente se observou a utilização do Jamelão ou Jambolão (em Belém nomeado ameixa e no Oeste do Pará azeitona) (Syazygium jambolanum), da Caapeba da Amazônia ou Malvarísco (Pothomorphe peltata (L.) Miq.) e do Caruru de Soldado (Amaranthus spinosus), por pessoas que interagem na ambiência da instituição de ensino. Existem no local dois exemplares de Jamelão, apenas um, no entanto, já está produzindo frutos. Quando alguns frutos já estiverem maduros a frequência de estudantes e professores será constante e a quantidade de frutos produzidos, muito inferior em relação às pessoas que querem consumi-los.

As folhas das Caapebas da Amazônia que estão sendo manejadas desde janeiro de 2018 foram solicitadas por um senhor que trabalha no setor de apoio, para serem utilizadas na cura de um parente acometido de erisipela. Questionado sobre o porquê do uso, afirmou que "morava no interior e lá aprendeu que o malvaísco cura erisipela" (informação verbal) ${ }^{1}$.

Quanto à planta Caruru de Soldado, um senhor que trabalha na portaria a cultiva no quintal da sua casa, no bairro da Terra Firme, para uso alimentício e declarou conhecer o vegetal como alimento a partir dos hábitos alimentares de um amigo residente em área rural. Dois pais de alunos declaram conhecer o uso pelos seus pais e avós, mas que na atualidade não fazem nenhum uso desta planta.

As demais PANC que se desenvolvem nos terrenos da instituição de ensino não foram utilizadas nem mencionadas por nenhum dos sujeitos que vivenciam o espaço socioambiental escolar. Os estudantes de uma turma de ensino médio observando um professor fazer a degustação das flores do Ipê rosa, degustaramnas in natura, no entanto durante o período de floração não se observou nenhuma outra pessoa do convívio escolar se interessar pelo consumo das ditas flores.

O maior problema enfrentado com o manejo das PANC no ambiente do educandário diz respeito aos períodos de roçagem, pois o desconhecimento da utilidade das plantas pelos trabalhadores das empresas que executam as roçagens

Informação fornecida por Waldemar Silva, em Belém Pará, no dia 22 de setembro de 2019. 
leva à eliminação da maioria das PANC, porém a condição biológica de plantas espontâneas e resilientes permite o novo desenvolvimento desses vegetais.

A E.E.E.F.M. "Mário Barbosa” completou 25 anos de práticas educativas em 2019, durante esse tempo, o seu ambiente recebeu importante arborização executada por seus docentes e foi impactado por insistentes e necessárias roçagens. Em diversas ocasiões as ditas roçagens atacavam, por desconhecimento e/ou falta de atenção, as próprias plantas cultivadas pelos professores. As ervas daninhas, os "matos" eram em última instância para serem eliminados ou controlados pela execução do referido trabalho.

Nesse período as caapebas da Amazônia eram sistematicamente suprimidas juntamente com carurus de soldado, beldroegas, jurubebas, ervas de jabuti, marias pretinhas, urtigas, camapus. A partir de 2018 essas ações de controle ambiental passaram a conviver com outros paradigmas.

Os conhecimentos sobre as PANC a partir da pesquisa de campo passaram a oferecer novas possibilidades de estudos, orientações e manejos, assim como passou a dinamizar outros discursos, os quais já afirmam que essas plantas não são ervas daninhas, nem são "matos", mas sim "plantas comestíveis", entendidas enquanto recursos naturais que podem auxiliar na melhoria da merenda escolar. Também se passou a ter melhor observação sobre os espaços do ambiente da escola e novas orientações sobre as plantas, em especial junto aos estudantes e trabalhadores que realizam as roçagens. Sobre mudanças nos discursos, sentidos e valores sobre as PANC Junqueira e Perline (2019) afirmam:

em torno desses vegetais, ou de suas partes, vem se instaurando um conjunto de discursos, que gradativamente se revelam impregnados de sentidos e valores não apenas afetos aos campos semânticos da alimentação e da nutrição, mas também aos das esferas contemporâneas da estética, da política, da ideologia e da ética (JUNQUEIRA; PERLINE, 2019, p. 19-20).

Portanto, neste novo discurso, deve-se observar que mais do que prover como ingredientes e nutrientes alternativos para as dietas, a utilização das PANC, leva a exercitar uma visão de engajamento ativo em favor da defesa da biodiversidade e da indicação para uma elaboração social no contexto de mercados mais socialmente justos, economicamente viáveis e ambientalmente sustentáveis.

Assim, fica evidente a importância da complementaridade entre os saberes tradicionais e científicos sobre as plantas alimentícias endógenas ou exógenas na Amazônia, para o processo de conhecimento e manutenção da diversidade vegetal e para a educação ambiental de adultos, crianças, docentes, discentes; utilizando como 
ferramentas a proatividade pedagógica entre a Educação Formal em dialogicidade com as práticas populares de transmissão de conhecimentos (LEFF, 2002).

A participação dos estudantes, seja no manejo, degustação das PANC e/ ou nas apresentações desses vegetais na feira científico-cultural da escola, amplia a cada ano os seus conhecimentos escolares e cria símbolos positivos para a relação socioambiental dos discentes com a diversidade vegetal na Amazônia.

O ambiente que antes era apenas um espaço para as roçagens foi transformado em local de experimento para o ensino-aprendizagem, e a gestão desses recursos naturais que, juntamente com a horta de plantas alimentícias convencionais, iniciada em novembro de 2019, já realiza a utilização das PANC na Merenda Escolar e motiva também a continuidade das visitas livres para o consumo das frutas diretamente das árvores, porém, agora desenvolvendo outros conhecimentos e valores sobre essa flora e a sua importância nutricional.

Desde quando o pesquisador alemão Kunkel (1984) iniciou a catalogação de plantas não tradicionais para o consumo alimentar, apresentando cerca de 12,5 mil espécies identificas em todo o mundo, agora somadas às pesquisas do professor Valdely Kinupp (2007, 2014) e demais trabalhos realizados no Brasil, na Amazônia e em outros lugares do planeta se faz um movimento decolonial do pensamento sobre as plantas alimentícias, se constrói resistências em relação à monocultura do saber e à imposição limitante do uso de plantas alimentícias implementada pelo agronegócio mundial.

Esses estudos também podem ser pensados como uma ferramenta para a sustentabilidade da diversidade vegetal que promova a compreensão mais eficaz do uso desses recursos naturais e que fortaleçam a economia de cidades como Belém, no sentido em que o manejo e a produção dessas plantas podem aumentar a oferta mais plural de alimentos, portanto, promover, diversificar e melhorar a qualidade nutricional e a saúde das populações. É importante ressaltar que esses vegetais se tornaram centro de atenção das chamadas expedições botânicas urbanas com finalidades culinárias, seguindo tendência observada na gastronomia internacional, cuja expressão original na língua inglesa é foraging (JUNQUEIRA; PERLINE, 2019).

E ainda que erice (2011) vislumbre com perspicaz crítica acadêmica o possível etnocentrismo retratado nas entrelinhas do título "Plantas Alimentícias Não Convencionais", em especial quando seus entrevistados questionam: "essa (planta) não pode ser não convencional, me criei comendo isso"; "ela é realmente considerada PANC?”; “essa, todo mundo conhece!” (ERICE, 2011, p. 20); é fato que, no ambiente da E.E.E.F.M. "Mário Barbosa” apenas a Syzygium cumini 
(L) Skeels - azeitona-preta, ameixa ou jamelão, uma planta exógena, é conhecida por "todo mundo", as demais eram totalmente desconhecidas ou muito pouco conhecidas e, na sua imensa maioria, ainda estavam subutilizadas e por consequência, esse importante recurso natural era desperdiçado.

Paschoal e Souza (2015) alertam para a possível presença de fitoquímicos tóxicos ou fatores antinutricionais que algumas PANC podem apresentar se consumidas de forma inapropriada, no entanto todas as 15 plantas identificadas na pesquisa estão reconhecidas como alimentícias por Kinupp (2007) e Kinupp (2014). O trabalho publicado em 2014 pelo referido autor apresenta a forma de preparo e três receitas ilustradas de cada PANC, que são as referências basilares para a produção do Guia Prático de PANC, que é o produto desta pesquisa para as possíveis aplicabilidades.

No ambiente da escola e no seu entorno se identificou 15 PANC: 1-Amaranthus spinosus L., 2-Cecropia pachystachya., 3-Ceiba pentandra (L.) Gaertn., 4-Handroanthus chrysotrichus (Mart. ex A. DC.), 5-Handroanthus impetiginosus (Mart. ex DC.) Mattos, 6-Laportea aestuans (L.) Chew, 7-Musa spp., 8-Peperomia pelúcida (L.) Kunth, 9-Physalis angulata L., 10- Piper peltatum L., 11-Portulaca oleracea, 12-Solanum americanum Mill., 13-Solanum paniculatum Jacq., 14-Syzygium cumini(L) Skeels, 15-Xanthosoma sagittifolium (L.). A seguir, apresentam-se algumas dessas PANC.

O Amaranthus spinosus L., o Caruru de soldado, é identificado e reconhecido como planta alimentícia por três pais de discentes da escola. Kinupp (2007) informa que sua reprodução acontece por meio de sementes e alerta para na hora da colheita dos ramos e das folhas para usá-los como alimento, dar toda atenção aos espinhos que se desenvolvem quando esta planta atinge a sua maturação.

Figura 1 - Amaranthus spinosus L., o caruru de soldado

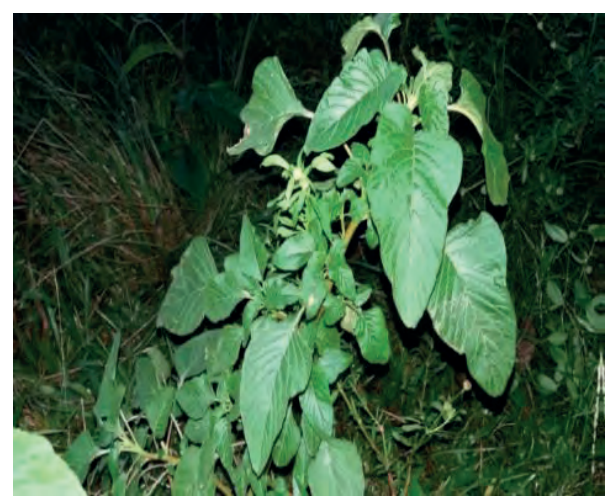

Fonte: Aquino (2017, p. 36). 
Cecropia pachystachya. A Imbaúba é uma árvore com vários nomes populares: embaúba, imbaúba, umbaúba, umbaubeira, ambaíba, árvore-da-preguiça e umbaúba-do-brejo. É uma das primeiras plantas a brotarem em áreas degradadas, fundamentais para o início do reflorestamento, seus frutos são muito apreciados por pássaros e as folhas fornecem os principais alimentos para a preguiça. $O$ naturalista francês Paul Le Cointe, em 1947, já afirmava que os frutos dispostos em cachos eram comestíveis, doces, acídulos e mucilaginosos, parecidos com a textura das uvas, mas com cheiro de salicilato de methylo. (LE COINTE, 1947). No processo de pesquisa se fez a coleta e degustação dos frutos in-natura com estudantes de Ensino fundamental e Médio, moradores da Comunidade Nossa Senhora dos Navegantes, nos anos de 2018 e 2019.

Figura 2 - Imbaúba, Cecropia pachystachya Trécul

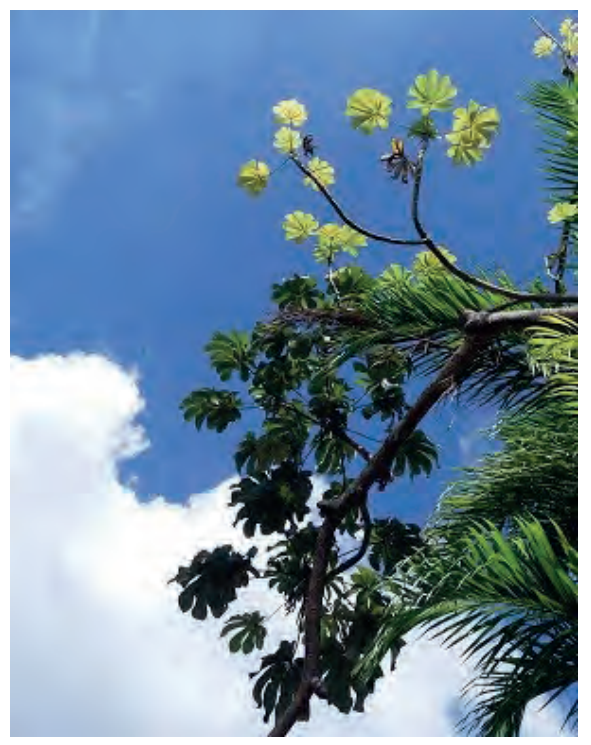

Fonte: Aquino (2020, p. 44).

Ceiba pentandra (L.) Gaertn. (Samaúma) é uma árvore de grande porte, nativa da Amazônia, pode atingir até 50 metros de altura e 2 metros de diâmetro. A sumaúma representa uma alternativa econômica importante para o produtor rural, em virtude dos múltiplos usos, isto é, madeira, paina e medicinais diversos (SANTOS, 2002). É cultivada ocasionalmente para fins paisagísticos. Suas folhas são comestíveis e apesar do grande tamanho das árvores na natureza, sempre existem árvores jovens nas quais seja possível a coleta de suas folhas (KINUPP, 2014). Não se encontraram em nenhuma literatura as especificações nutricionais das folhas da samaúma. 
Figura 3 - Samaúma, Ceiba pentandra (L.) Gaertn, com folhas tenras

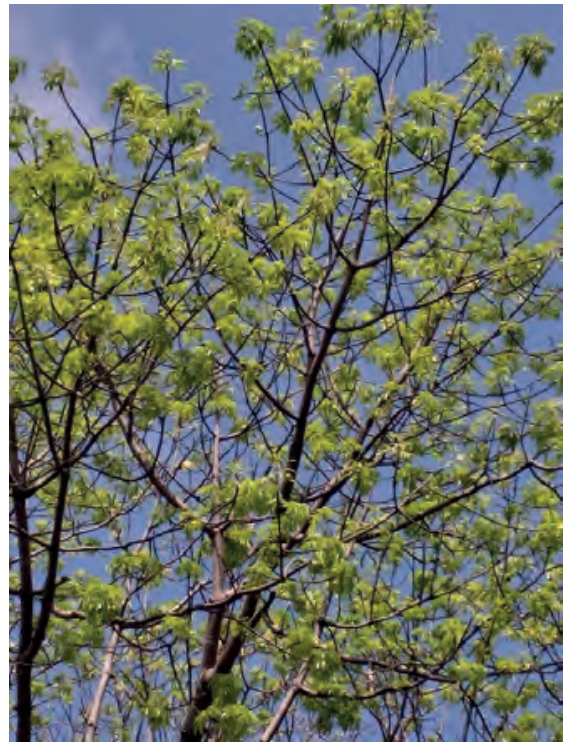

Fonte: Aquino (2020, p. 46).

Handroanthus chrysotrichus (Mart. ex A. DC.) Ipê-amarelo e Handroanthus impetiginosus (Mart. ex DC.) Mattos Ipê-rosa são árvores de folhagem decídua durante o inverno, na Amazônia floram entre os meses de agosto e outubro, atingem 4 a $10 \mathrm{~m}$ de altura, com tronco suberoso de 30 a $40 \mathrm{~cm}$ de diâmetro. Estas árvores são amplamente cultivadas na arborização urbana com fins ornamentais, as flores, além de seu papel na ornamentação, são comestíveis, tanto para o consumo cru, na forma de salada, como cozidas e preparada de várias formas (KINUPP, 2014). Ambas as espécies estão presentes no ambiente da E.E.E.F.M. "Mário Barbosa” e sua floração já é observada desde 2016.

Figura 4 - Handroanthus impetiginosus, o ipê rosa

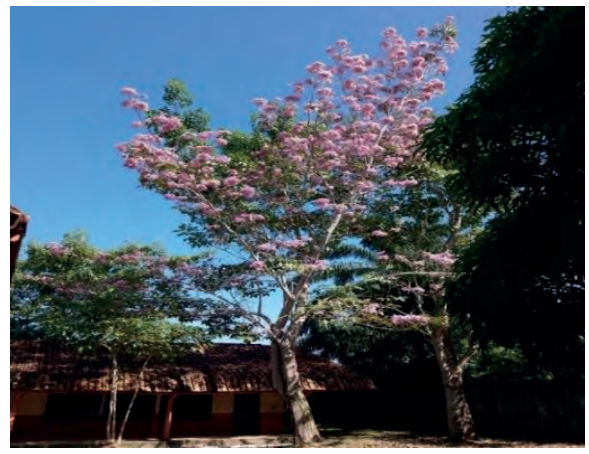

Fonte: Aquino (2020, p. 47). 
Laportea aestuans (L.) Chew. Entre as diferentes urtigas identificadas pela botânica está a U. dioica, a qual possui características muito semelhantes à Laportea aestuans (L.) Chew. "A U. dioica foi amplamente consumida durante a idade média na Europa, o que influenciou na atualidade, a criação da Confraria da urtiga, em 2009 em Fornos-de-Algarves" (SILVA, 2017, p. 3), isso evidencia que o uso de várias dessas plantas já ocorreu em outros momentos históricos. Kinupp (2014) recomenda que as folhas da Laportea aestuans (L.) Chew sejam escaldadas antes do uso, porém este autor em um encontro sobre as PANC em Belém a consumiu in-natura depois de friccionar bem o lado urticante da folha.

Figura 5 - Laportea aestuans (L.) Chew, a urtiga vermelha

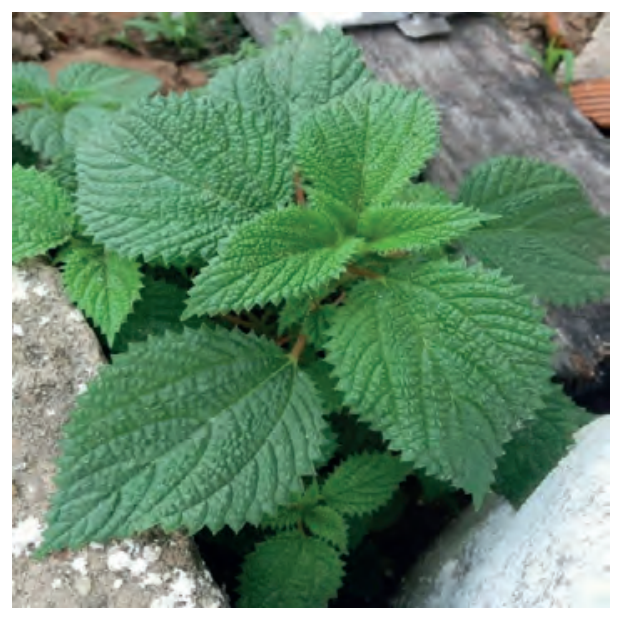

Fonte: Aquino (2020, p. 49).

\section{ALGUMAS RECEITAS DE PANC}

\subsection{BOLINHO DE FOLHAS DE SAMAUMEIRA}

Colha apenas os ramos terminais jovens e retire as folhas bem tenras (verde-avermelhadas). Lave e pique fininho. Bata 4 ovos, sal e temperos (orégano, alho, pimenta) a gosto e 12 colheres (sopa) de farinha de trigo. Incorpore várias folhas picadas à massa e misture bem. Frite em óleo bem quente. Escorra em papel toalha e sirva quente. 
Figura 6 - Receitas Ilustradas: Ceiba pentandra (L.) Gaertn. samaúma

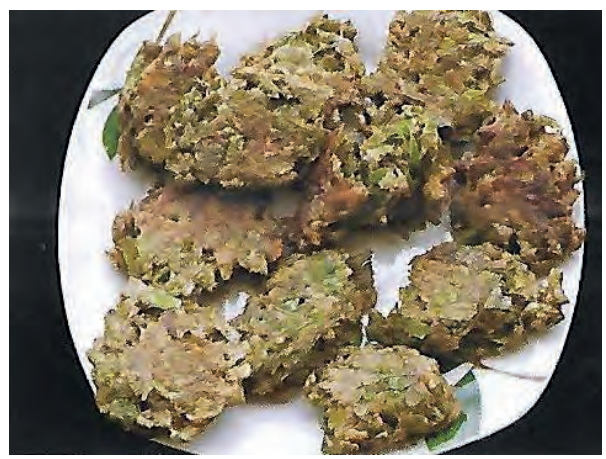

Fonte: Kinupp (2014, p. 621).

\subsection{REFOGADO DE BELDROEGA COM LINGUIÇA}

Colha os ramos tenros ou compre nas feiras (disponíveis em algumas cidades de Norte a Sul do Brasil, especialmente nas feiras orgânicas). Lave, desfolhe e quebre em pedaços os talos. Doure alho, sal e outros temperos a gosto na manteiga ou azeite e acrescente linguiça fatiada. Deixe fritar bem, acrescente a beldroega e mexa. Deixe murchar rapidamente em fogo baixo e sirva quente.

Figura 7 - Receitas Ilustradas: Portulaca oleracea L. beldroega

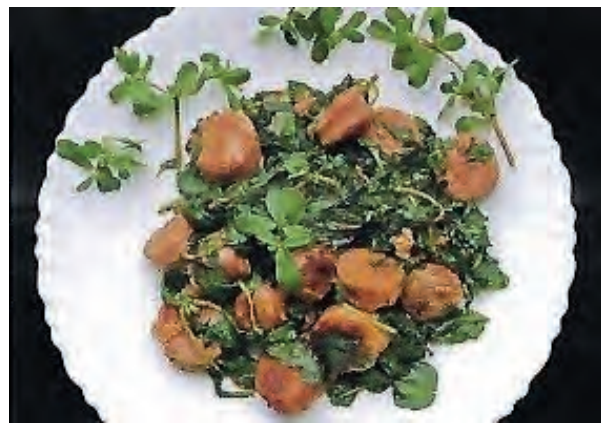

Fonte: Kinupp (2014, p. 699).

\subsection{URTIGA-VERMELHA À MILANESA}

Use luvas. Colha plantas jovens e selecione folhas viçosas, lave-as coletivamente e escorra. Bata 4 ovos em um prato com sal, orégano, alho e demais temperos a gosto. Passe as folhas no ovo e passe na farinha de rosca (ou de trigo - à doré). Se desejar passe novamente no ovo e na farinha (opcional). 
Frite no óleo bem quente. Escorra e seque em papel toalha. Sirva quente. Fica linda devido às bordas denteadas. Ideal para aulas de morfologia (comestível).

Figura 8 - Receitas ilustradas: Laportea aestuans (L.) Chew. urtiga vermelha

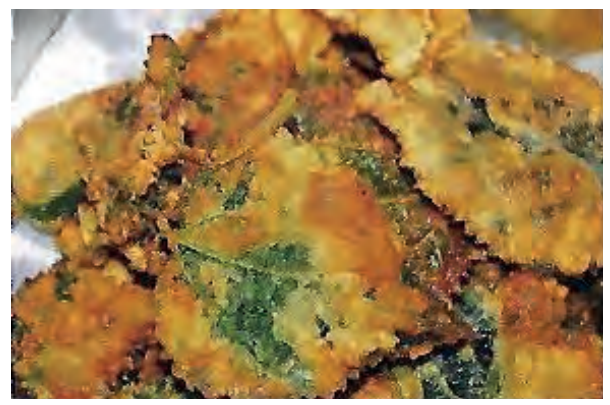

Fonte: Kinupp (2014, p. 599).

\subsection{CHARUTO DE CAAPEBA-AMAZÔNICA}

Branqueie as folhas sem talo. Misture 500g de carne moída (2x), 2 xícaras de arroz, azeite e sal a gosto. Estique as folhas com a parte superior para baixo. Coloque o recheio próximo à ponta e, com a palma da mão, enrole. Forre a panela com folhas abertas e coloque os charutinhos em camadas alternando com uma mistura de alho, sal e hortelã socados. Cubra com água e cozinhe. Ao final, junte o suco de limão e deixe por mais 5 minutos. Sirva quente.

Figura 9 - Receitas Ilustradas: Piper peltatum L. caapeba amazônica

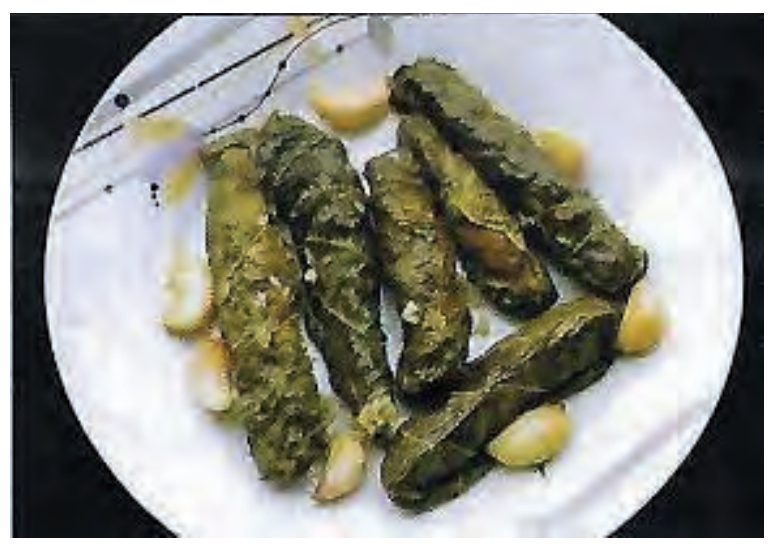

Fonte: Kinupp (2014, p. 661). 


\section{CONSIDERAÇÕES FINAIS}

As PANC identificadas, ainda que pouco utilizadas pela grande maioria das pessoas, estão todas catalogadas cientificamente e com rico material acadêmico disponível para estudo, como pode ser mostrado na apresentação do estado da arte. Não se encontrou referenciais sobre as qualidades nutricionais relacionadas às folhas do camapu, às flores do Ipê amarelo e do Ipê rosa, assim como em relação aos frutos da Imbaubeira e as folhas da Samaumeira, indicando a necessidade de mais estudos sobre as características físico-químicas dessas plantas.

A qualidade e diversidade de sais minerais, vitaminas, lipídios, carboidratos proteínas e fibras descritos nos estudos das demais plantas evidenciam a possibilidade do uso dessas plantas ou partes delas na composição nutricional exigida pelo Programa Nacional de Merenda Escolar, verificou-se que podem ser utilizadas para consumo em receitas básicas da culinária paraense na merenda escolar.

Bons exemplos são as características nutricionais da Beldroega (Portulaca oleracea), "por exemplo, é rica em ômega 3" (CORREA, 2017, p. 12), "além de microminerais como de $\mathrm{Cu}, \mathrm{Zu}, \mathrm{Fe}, \mathrm{Mn}, \mathrm{B}$ e macrominerais a exemplo de $\mathrm{P}, \mathrm{K}, \mathrm{Ca}$, Mg, S” (MANGOBA, 2015, p. 71). Quanto à Solanum americanum Mill., conhecida popularmente como Maria pretinha, pesquisada na Guatemala em análises cruas ou cozidas (ambas em base Úmida) apresentam a "composição centésima (g/100g): umidade $(87,5)$; proteínas $(3,9)$; lipídios $(0,9)$; carboidratos $(3,8)$; cinzas (1,2); fibra (1,4g); Ca (180); P (53); Fe (6); K (129); Mg (81)" (KINUPP, 2007).

Os resultados do manejo das PANC no ambiente da E.E.E.F.M. "Mario Barbosa" indicam que é possível o seu cultivo em conjunto e complementaridade com as plantas convencionais presentes nos espaços livres da instituição de ensino e oportuniza um ambiente multidisciplinar para ser desenvolvido no processo de ensino-aprendizagem.

O estudo aponta possibilidades de pesquisas sobre os valores medicinais e nutracêuticos dessas plantas e a compreensão multidisciplinar a partir dos conteúdos próprios dos Ensinos Fundamental e Médio.

\section{REFERÊNCIA}

A FOME afeta 42,5 milhões de pessoas na América Latina e no Caribe.

Organização das Nações Unidas. Escritório Regional da FAO para a América Latina e o Caribe, Santiago, 2019. Notícias. Disponível em: http:/ / www.fao.org/americas/noticias/ver/pt/c/1201842/. Acesso em: 10 jan. 2020. 
AGENDA 2030. Agenda 2030. Nações Unidas Brasil, Brasília, DF, 2015. Disponível em: https:/ / nacoesunidas.org/pos2015/agenda2030/. Acesso em: 17 jan. 2019.

ALCANTARA, C. S.; SAMPAIO, C. A. C. Bem viver como paradigma do desenvolvimento: utopia ou alternativa. Desenvolvimento e meio ambiente, Curitiba, v. 40, p. 231-251, abr. 2017.

ALVES, K. V. Chef do AM usa plantas alimentícias não comestíveis e cria pratos saborosos. D24am Gourmet, Manaus, 13 nov. 2016. Disponível em: https://d24am.com/plus/gourmet/chef-usa-plantas-alimenticias-naoconvencionais-e-cria-pratos-saborosos/. Acesso em: 07 jan. 2019.

AQUINO, D. R. M. Plantas Alimentícias Não Convencionais no contexto da educação ambiental: o conhecimento tradicional de plantas alimentícias não convencionais (PANC) na comunidade Nossa Senhora dos Navegantes (Ilha da Várzea do Rio Aurá), no município de Belém. 2017. Artigo (Especialização em Educação Ambiental e Sustentabilidade) — Núcleo de Meio Ambiente, Universidade Federal do Pará, Belém, 2017.

\section{AQUINO, D. R. M. Plantas Alimentícias Não Convencionais em}

Belém-Pará: conhecimento, usos e segurança alimentar. 2020. Dissertação (Mestrado em Gestão dos Recursos Naturais e Desenvolvimento Local na Amazônia) - Programa de Pós-Graduação em Gestão dos Recursos Naturais e Desenvolvimento Local na Amazônia, Núcleo de Meio Ambiente, Universidade Federal do Pará, Belém, 2020.

ARDISSONE, R. E. et al. Biodiversidade pela boca: Plantas Alimentícias Não Convencionais (PANC). Projeto de Extensão: estudos e práticas de viveirismo em um centro de formação de agricultores. Santa Cruz do Sul: Instituto de Biociência-UFRGS: Cooperfumos, MPA: Centro de Formação em Bioenergia e Alimentos São Francisco de Assis, 2009. 22 p.

ARRUDA, R. "Populações tradicionais" e a proteção do ambiente e sociedade. Revista Ambiente e Sociedade, Campinas, n. 5, p. 79-92, 1999.

BELÉM. Lei $\mathbf{n}^{\circ}$ 7.603, de 13 de janeiro de 1993. Dispõe sobre o Plano Diretor do Município de Belém e dá outras providências. Belém: Câmara Municipal de Belém, [1993]. Disponível em: encurtador.com.br/pFTW9. Acesso em: 15 ago. 2020. 
BOFF, L. Sustentabilidade: o que é / o que não é. Petrópolis, RJ: Vozes, 2012. BRANDÃO, C. R. Vocação de criar: anotações sobre a cultura e as culturas populares. Cadernos de Pesquisa Fundação Carlos Chagas, São Paulo, v. 39, n. 138, p. 715-746, set./dez. 2009.

BRASIL. [Constituição (1988)]. Constituição da República Federativa do Brasil. Brasília, DF: Presidência da República, [1988]. Disponível em: http:// www.planalto.gov.br/ccivil_03/constituicao/constituição.htm. Acesso em: 16 ago. 2020 .

BRASIL. Lei $\mathbf{n}^{\mathbf{0}} \mathbf{1 1 . 3 4 6}$, de 15 de setembro de 2006. Cria o Sistema Nacional de Segurança Alimentar e Nutricional [...]. Brasília, DF: Presidência da República, [2006]. Disponível em: encurtador.com.br/avxBR. Acesso em: 16 ago. 2020 .

BRASIL. Lei $\mathrm{n}^{\circ}$ 11.947, de 16 de junho de 2009. Dispõe sobre o atendimento da alimentação escolar [...]. Brasília, DF: Presidência da República, [2009]. Disponível em: http://www.planalto.gov.br/ccivil_03/_ato2007-2010/2009/ lei/111947.htm. Acesso em: 16 ago. 2020.

BRASIL. Ministério da Agricultura, Pecuária e Abastecimento. Secretaria de Desenvolvimento Agropecuário e Cooperativismo. Manual de hortaliças não convencionais. Brasília, DF: MAPA, 2010a. 92 p.

BRASIL. Decreto $\mathbf{n}^{\mathbf{0}} \mathbf{7 . 2 7 2}$, de 25 de agosto de 2010. Regulamenta a Lei $\mathrm{n}^{\circ}$ 11.346, de 15 de setembro de 2006 [...]. Brasília, DF: Presidência da República, [2010b]. Disponível em: http://www.planalto.gov.br/ccivil_03/_Ato20072010/2010/Decreto/D7272.htm. Acesso em: 16 ago. 2020.

BRASIL. Ministério da Saúde. Secretaria de Atenção à Saúde. Departamento de Atenção Básica. Alimentos regionais brasileiros. 2. ed. Brasília, DF: Ministério da Saúde, 2015. 484 p.

CAVALCANTE, P. B. Frutas comestíveis da Amazônia. 7. ed. rev. e atual. Belém: Museu Goeldi, 2010. 280 p.

COGGIOLA, O. Fome, capitalismo, e programas sociais compensatórios: histórico e análise comparada da experiência brasileira. São Paulo: USP, 2010. 70 p. CORREA, A. R. Fenologia e produção de mudas de Portulaca oleracea subsp. sativa em clima tropical. 2017. Dissertação (Mestrado em Agricultura Tropical) - Programa de Pós-Graduação em Agricultura Tropical, Universidade Federal do Mato Grosso, Cuiabá, 2017. 
D’ABBEVILLE, C. História da missão dos padres capuchinhos, na Ilha do Maranhão e suas circunvizinhanças. São Luiz: Typ. do Frias, 1874. D'ÉVREUX, Y. Continuação da história das coisas mais memoráveis acontecidas no Maranhão nos 1613 e 1614. Tradução de César Augusto Marques. Brasília, DF: Senado Federal, 2007. 496 p.

DIA DE CAMPO da Embrapa discute plantas alimentícias não convencionais. FAPEG, Goiânia, 22 fev. 2018. Disponível em: http:/ /www.fapeg.go.gov.br/ dia-de-campo-da-embrapa-discute-plantas-alimenticias-nao-convencionais/. Acesso em: 21 abr. 2018.

DUARTE, G. Levantamento e caracterização das Plantas Alimentícias Não Convencionais do Parque Florestal de Monsanto - Lisboa. Lisboa: FCSH, 2017. 95 p.

EPAGRI. Cultivo de PANC aumenta a diversidade alimentar e a renda dos agricultores. EPAGRI, Florianópolis, 2020. Disponível em: https:/ / www.epagri.sc.gov.br/index.php/2020/02/26/cultivo-de-panc-aumenta-adiversidade-alimentar-e-a-renda-dos-agricultores/. Acesso em: 15 ago. 2020.

ERICE, A. S. Cultivo e comercialização de Plantas Alimentícias Não Convencionais (PANC) em Porto Alegre. 2011. Trabalho de Conclusão de Curso (Graduação em Ciências Biológicas) - Instituto de Biociências, Universidade Federal do Rio Grande do Sul, Porto Alegre, 2011.

EZPELETA, J.; ROCKWELL, E. Pesquisa participante. Traduzido por Francisco Salatiel de Alencar Barbosa. São Paulo: Cortes: Autores Associados, 1989. 92 p.

FENZL, N. O conceito de desenvolvimento sustentável em sistemas abertos. Poematropic, [S. l.], v. 1, n. 1, p. 34-42, jan./jun. 1998.

FERNANDES, J. A. De cunhã a mameluca: a mulher tupinambá e o nascimento do Brasil. 2. ed. João Pessoa: UFPB, 2016.

FLANDRIN, J. L. História da alimentação. 8. ed. São Paulo: Estação Liberdade, 2015.

FRANÇA, V. Chefs renomados apostam em pratos com plantas exóticas para surpreender o paladar. Forbes, São Paulo, 05 nov. 2017. Disponível em: https:/ / forbes.com.br/forbeslife/2017/11/chefs-renomados-apostam-empratos-com-plantas-exoticas-para-surpreender-o-paladar/. Acesso em: 12 ago. 2020 . 
GÂNDAVO, P. M. A primeira história do Brasil: história da Província Santa Cruz a que vulgarmente chamamos Brasil. 2. ed. Rio de Janeiro: Jorge Zahar Editor, 2004.

JUNQUEIRA, A. H.; PERLINE, E. A. Gosto, ideologia e consumo alimentar: práticas e mudanças discursivas sobre as Plantas Alimentícias Não Convencionais - PANC. Cadernos de Linguagem e Sociedade, Brasília, DF, v. 20, n. 2, p. 17-35, 2019.

KELEN, M. E. B. et al. Plantas Alimentícias Não Convencionais (PANCs): hortaliças espontâneas e nativas. Porto Alegre: UFRGS, 2015. Disponível em: https://www.ufrgs.br/viveiroscomunitarios/wp-content/uploads/2015/11/ Cartilha-15.11-online.pdf. Acesso em: 30 jan. 2019.

KINUPP, V. F. Plantas Alimentícias Não Convencionais da região metropolitana de Porto Alegre. Porto Alegre: UFRGS, 2007.

KINUPP, V. F. Plantas Alimentícias Não Convencionais (PNACs): uma riqueza negligenciada. In: REUNIÃO ANUAL DA SBPC, 61., 2009, Manaus. Anais [...]. Manaus: SBPC, 2009. p. 1-4.

\section{KINUPP, V. F. Plantas Alimentícias Não Convencionais (PANC) no}

Brasil: guia de identificação, aspectos nutricionais e receitas ilustradas. São Paulo: Instituto Plantarum de Estudo da Flora, 2014.

KUNKEL, G. Plants for human consumption. Koenigsten: Koeltz Scientific Books, 1984. 393 p.

LARRAT, H. J. F. M. Pobreza e violência urbana: um estudo de casos sobre as políticas sociais públicas e de segurança pública de prevenção e combate à pobreza e à violência, no bairro da Terra Firme em Belém-PA. 2013.

Dissertação (Mestrado em Meio Ambiente e Desenvolvimento Urbano) Programa de Pós-Graduação em Meio Ambiente e Desenvolvimento Urbano, Universidade da Amazônia, Belém, 2013.

LE COINTE, P. Amazônia brasileira III: árvores, plantas, úteis (indígenas e aclimadas). 2. ed. Ilustrada. São Paulo: Companhia Editora Nacional, 1947.

LEFF, E. Epistemologia ambiental. Tradução de Sandra Valenzuela. São Paulo: Cortez, 2002.

LISBOA, P. L. B. (org.). Aurá: comunidades e florestas. Belém: MPEG, 2009.

LOPES, R. J. 1499: A pré-história do Brasil. Rio de Janeiro: Harper Collins, 2017. 
MALINOWSKI, B. K. Argonautas do Pacífico ocidental: um relato do empreendimento e da aventura dos nativos nos arquipélagos da Nova Guiné Melanésia. 2. ed. São Paulo: Abril Cultural, 1978.

MANGOBA, P. M. A. Prospecção de características fitoquímicas, antibacterianas e físico-químicas de Portulaca oleracea L. (Beldroega). 2015. Dissertação (Mestrado em Ciência e Tecnologia de Alimentos) - Programa de Pós-Graduação em Ciência e Tecnologia de Alimentos, Universidade Federal do Rio Grande do Sul, Porto Alegre, 2015.

MAZOYER, M. 1933: história das agriculturas no mundo: do neolítico à crise contemporânea. São Paulo: Editora UNESP; Brasília, DF: NEAD, 2010.

MOLDELSK, V. Explorando jardins comestíveis via Plantas Alimentícias Não Convencionais com mulheres do Movimento dos Trabalhadores Rurais Sem Terra do Assentamento Filhos de Sepé. 2015. Trabalho de Conclusão de Curso (Graduação em Ciências Biológicas) - Instituto de Biociências, Universidade Federal do Rio Grande do Sul, Porto Alegre, 2015. PASCHOAL, V.; SOUZA, N. S. Plantas Alimentícias Não Convencionais (PANC). In: CHAVES, D. F. S. (org.). Nutrição clínica funcional: compostos bioativos dos alimentos. São José do Rio Preto: VP Editora, 2015. p. 302-323.

PESCE, C. Oleaginosas da Amazônia. 2. ed. Belém: MPEG: NCADR, 2009. $334 \mathrm{p}$.

PIMENTEL, E. M. Leitura de poemas: uma proposta para o ensino fundamental. 2015. Dissertação (Mestrado em Letras em Rede Nacional) Programa de Pós-Graduação em Mestrado Profissional em Letras em Rede Nacional, Universidade Federal do Pará, Belém, 2015.

RENAUX, P. Pobreza aumenta e atinge 54,8 milhões de pessoas em 2017. Agência IBGE, Rio de Janeiro, 05 dez. 2018. Síntese de indicadores sociais. Disponível em: https://agenciadenoticias.ibge.gov.br/agencia-noticias/2012agencia-de noticias noticias/noticias/23299-pobreza-aumenta-e-atinge-54-8milhoes-de-pessoas-em-2017. Acesso em: 11 dez. 2018.

RESTAURANTE traz receitas com PANC. Garfo e Mala, Porto Alegre, 2017. Disponível em: https://garfoemala.com.br/restaurante-traz-receitas-feitascom-plantas-alimenticias-nao-convencionais/. Acesso em: 18 abr. 2018.

REVISTA KATÁLYSIS. Florianópolis: UFSC, v.17, n. 1, 2014. 
SANTOS, B. S. Conhecimento prudente para uma vida decente: um discurso sobre as ciências revisado. 2. ed. São Paulo: Cortez, 2006. 821 p. SANTOS, S. H. M. Recomendações técnicas da Samaúma. Belém, PA: EMBRAPA, 2002. 4 p.

SEVERINO, A. J. Metodologia do trabalho científico. 24. ed. São Paulo: Cortez, 2016. 317 p.

SILVA, J. O. Caracterização e atividade biológica de urtiga selvagem. Bragança: Instituto Politécnico de Bragança, 2017. 95 p.

SOUZA, G. S. Tratado descritivo do Brasil em 1587. Belo Horizonte: Editora Itatiaia, 2000. $382 \mathrm{p}$.

VERÍSSIMO, J. Cenas da vida amazônica. 4. ed. Belém: Editora Estudos Amazônicos, 2013. 32 p.

WALSH, C. Interculturalidade crítica e pedagogia decolonial: in-surgir, reexistir, e re-viver. In: CANDAU, V. M. (org.). Educação Intercultural na América Latina: entre concepções, tensões e propostas. Rio de Janeiro: Departamento de Educação da PUC-Rio, 2009. 155 p. 
